\title{
Comparison of radiograph panoramic quality between conventional and indirect digital methods on mixed teeth period
}

\author{
Delsa Rosana Bella ${ }^{1}$, Rurie Ratna Shantiningsih², Isti Rahayu Suryani² \\ ${ }^{1}$ Study Program of Dental Hygienist, Faculty of Dentistry Gadjah Mada University, Indonesia \\ ${ }^{2}$ Department of Dentomaxillofacial Radiology, Faculty of Dentistry Gadjah Mada University, \\ Indonesia
}

\begin{abstract}
Introduction: Panoramic radiograph is an image used by the dentist to maintain diagnosis in dentistry, for example, to evaluate teeth condition in mixed dentition period. There are two panoramic radiography techniques, which are conventional and digital (direct and indirect) method. This study was aimed to analyse the differences of panoramic radiograph image quality between the conventional and digital indirect method on mixed dentition radiograph. Methods: Thirty samples of conventional and indirect digital panoramic radiograph were randomly taken from the database according to inclusion criteria. The image quality of conventional radiograph was manually assessed by using illuminator box, while indirect digital radiographs was assessed directly using DBS Win 5.7.0 software (Durr Dental, Germany). The radiographs were divided into six zones: teeth area, nasal and sinus, mandible, TMJ, ramus-spine, and hyoid bone. The image quality assessment was performed in each area based on three criteria: anatomical coverage, density and contrast, and anatomical structure. Results: The Cronbach's Alpha Intra-Class Correlation (ICC) inter and intraobserver agreement test of conventional and digital indirect methods on the aspect of anatomical, density and contrast coverage, and anatomic structure showed an excellent agreement. The independent sample t-test result showed significant difference $(p<0.05)$ between the conventional and indirect digital method in density and contrast as well as anatomical structure aspects, but not significantly different $(\mathrm{p}>0.05)$ in the anatomical coverage aspect. Conclusion: Indirect digital panoramic radiograph shows better image quality as compared to conventional radiograph, especially in the anatomical structure aspect, density and contrast. There is no difference in the anatomical coverage aspect between conventional and indirect digital panoramic radiograph.
\end{abstract}

Keywords: Panoramic radiograph, digital radiography, conventional radiography, image quality.

p-ISSN: 1979-0201; e-ISSN: 2549-6212; Available from: http://jurnal.unpad.ac.id/pjd/article/view/17047

DOI: 10.24198/pid.vol32no2.17047

Submission: Jun 15, 2018; Accepted: Jul 30, 2020; Published online: Jul 31, 2020

"Corresponding author: Rurie Ratna Shantiningsih, Department of Dentomaxillofacial Radiology, Faculty of Dentistry Gadjah Mada University, Indonesia. Department of Dentomaxillofacial Radiology, Faculty of Dentistry Gadjah Mada University, 1 , Jalan Denta, Yogyakarta, Special Region of Yogyakarta, Indonesia, 55281. Phone: +6281328712276; Email: rurieratna@ ugm.ac.id 


\section{INTRODUCTION}

Panoramic radiography is a radiograph that produces a single image of the facial structure, including the maxillary and mandibular teeth and their supporting structures. ${ }^{1}$ Panoramic radiographs are often used to detect eruption patterns, evaluate impact teeth, evaluate trauma, check enlargement of lesions, detect disease and see jaw condition. ${ }^{2}$ The result of the image quality of the panoramic radiograph depends on the appropriate method. ${ }^{3}$

Panoramic radiography is divided into two methods: conventional panoramic radiography and digital panoramic radiography. ${ }^{4}$ Conventional panoramic radiography is a radiographic method that the process of printing the film is done manually. Digital panoramic radiography is a radiographic method whose image capture process does not use film. The film is replaced by an electrostatic device that sends images to the computer so it can be instantly visible on the monitor screen. Digital radiography is divided into two types: direct digital radiography using Charge Couple Device (CCD) or Complementary Metal Oxide Semiconductor (CMOS) and indirect digital radiography using a wireless network system such as Photostimulable Phosphor Plate (PSP). ${ }^{5,6}$ Digital panoramic radiograph image easily manipulated, easily stored and retrieved, perfectly duplicated and easy to use for communicating with children, but the image resolution is lower than that of conventional panoramic radiographs. ${ }^{7,8}$

Mixed teeth are a period in which decidual dentition and permanent dentition are encountered simultaneously at the age period of 6-12 years. ${ }^{9}$ The use of panoramic radiographs in the mixed dentition period serves to evaluate the growth and development of teeth, early detection of dental anomalies, information of pathological conditions other than caries, and orthodontic treatment. ${ }^{7}$ One example of constraints on the process of radiographic imaging with pediatric patients is an excessive fear of children that can sometimes affect the quality of the resulting image. ${ }^{10}$ Appropriate radiographic methods in children can help the dentist to diagnose optimally. ${ }^{11}$ This study was aimed to analyse the differences in the panoramic radiograph image quality between the conventional method and digital indirect on mixed dentition period radiograph.

\section{METHODS}

This research was a comparative study with a sampling method using cross-sectional design type ${ }^{12}$, conducted in Dentomaxillofacial Radiology Installation of the Faculty of Dentistry Gadjah Mada University and patient's medical record from Prof Soedomo Dental Hospital. The research sample was conventional panoramic radiograph stored in mixed dentition patients' medical record from Prof Soedomo Dental Hospital and indirect digital panoramic radiographs that have been stored on the patients' radiograph database in Dentomaxillofacial Radiology Installation. The sample size was 30 samples for each conventional panoramic radiograph and digital indirect. Selection of research samples based on inclusion criteria: patient at the age of 6-12 years in the mixed dentition period, without craniofacial disorders and meeting quality assurance quality standards including good density and contrast, and radiographic images did not appear reversed or flat.

Image quality assessment on mixed dentition was performed on six panoramic radiograph zone, i.e. dentition (zone 1 ), nose and maxillary sinuses (zone 2), body of mandible (zone 3 ), temporomandibular joint (zone 4), ramus of mandible (zone 5), and hyoid bone (zone 6 ).

Assessment of the quality of conventional radiograph image was conducted directly by using illuminator box, digital indirect radiograph image

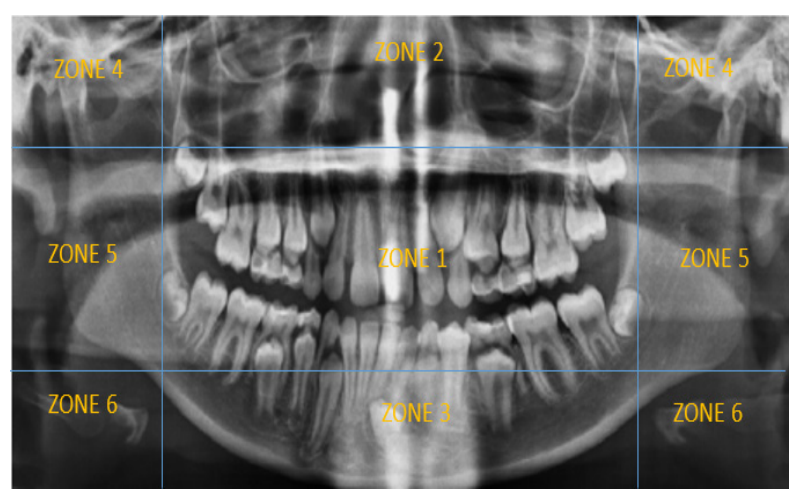

Figure 1. Division of the panoramic radiograph zone: dentition (zone 1), nose and maxillary sinuses (zone 2 ), mandibles (zone 3), TMJ (zone 4), spina ramus (zone 5) and hyoid bone (zone 6 ). ${ }^{13}$ 
quality evaluation was performed using software DBS Win 5.7.0, after the radiographs were being processed using high filter diagnostic. Radiograph image quality assessment was conducted in each zone with scoring on three aspects, which were anatomy, density and contrast coverage, and anatomical structure. Each aspect was assessed with a score range of 1 to 4 , with the score of 1

Table 1. Panoramic radiograph image quality score assessment ${ }^{13}$

\begin{tabular}{lcl}
\hline Aspect & Image score & \\
\hline \multirow{3}{*}{ Anatomy coverage } & 1 & Description \\
& 2 & The coverage of anatomy is not intact, allowing for diagnosis \\
& 3 & Full anatomical coverage, can be used for diagnosis \\
& 4 & Full anatomical coverage, optimal for diagnosis \\
\hline \multirow{3}{*}{ Density and contrast } & 1 & Bad density, bad contrast \\
& 2 & Density is bad, the contrast is pretty good \\
& 3 & Good density and contrast \\
& 4 & Density and contrast are excellent \\
\hline \multirow{2}{*}{ Anatomical structure } & 1 & The structure of anatomy is not obvious, can not be used for diagnosis \\
& 2 & Details are visible in part, the diagnosis is uncertain \\
& 3 & The visualised details are clearly visible only for small area, allowing for diagnosis \\
& 4 & The details are visualised, optimally used for diagnosis \\
\hline
\end{tabular}

showing the most ineadequate image quality and score 4 indicating the best image quality (Table 1).

Interobserver test was conducted by the writer and assistant of Dentomaksiofacial Radiology of UGM FKG with the same time at $10 \%$ of the total sample, and the sample was chosen randomly. The intraobserver test was performed by the author twice with a period of 1 week at $10 \%$ of the total sample size, and the sample was randomly selected. The reliability test used in the inter and intraobserver agreement test is Cronbach's alpha intra-class correlation (ICC) test.

Statistical tests were performed using SPSS devices. Intertest results and intraobserver agreement using Cronbach's alpha intra-class correlation (ICC) test. All measured data were checked using the Shapiro-Wilk test (Table 3) to see whether the data was normally distributed or not. If the data was normally distributed, then the different test would be performed using parametric statistical analysis of independent sample t-test. If the data was not normally distributed, then the non-parametric test would be tested by MannWhitney U-test.

\section{RESULTS}

Comparative research on the assessment of panoramic radiograph image quality between conventional and digital indirect methods at UGM Soedomo Dental Hospital on dental radiographs of mixed tooth patients was performed on 30 subjects meeting the inclusion and exclusion criteria. Table 2 shows the results of Cronbach's Alpha Intra-Class Correlation (ICC) inter and intraobserver agreement test of conventional and digital indirect methods respectively on the aspect of anatomical, density and contrast coverage, and anatomic structure showing excellent agreement.

Figure 2 shows that the average panoramic radiograph image quality on all aspects of indirect

Table 2. Interobserver agreement test results and intraobserver agreement test

\begin{tabular}{clcc}
\hline Method & \multicolumn{1}{c}{ Aspect } & Interobserver agreement & Intraobserver agreement \\
\hline Convensional & Anatomy coverage & 0.940 & 0.973 \\
& Density and contrast & 0.987 & 0.885 \\
& Anatomical structure & 0.952 & 0.857 \\
\hline Indirect digital & Anatomy coverage & 0.940 & 0.857 \\
& Density and contrast & 0.987 & 0.989 \\
& Anatomical structure & 0.952 & 0.987 \\
\hline
\end{tabular}




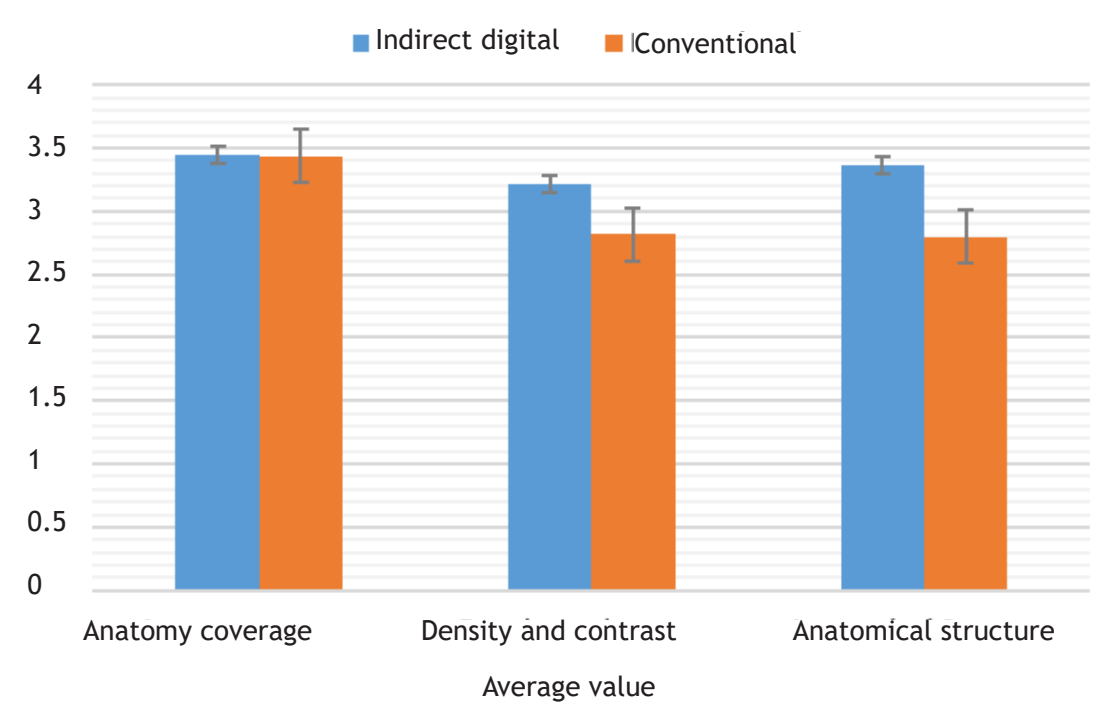

Figure 2. The average panoramic radiograph image quality assessment between conventional and digital indirect methods on mixed tooth period patients' radiograph

digital method was higher than conventional methods.
Based on data presented Table 3, it was known that the results of normality test of each

Table 3. Results of the Shapiro-Wilk test of panoramic radiograph image quality assessment between conventional and digital indirect methods on mixed tooth period patients' radiograph

\begin{tabular}{lcc}
\hline \multicolumn{3}{c}{ Shapiro-Wilk Test } \\
\hline & Conventional (Sig.) & Indirect digital (Sig.) \\
\hline Anatomy coverage & 0.665 & 0.280 \\
Density and contrast & 0.552 & 0.201 \\
Anatomical structure & 0.327 & 0.289 \\
Mean & 0.514 & 0.256 \\
\hline
\end{tabular}

Notes: Sig. $(p)=$ Significance

method in all aspects obtaining a significant value $(p>0.05)$, which means the results of the quality assessment of panoramic radiograph images between conventional and indirect digital methods on the mixed tooth period patients' radiograph was normally distributed.
Table 4 shows that the parametric results of independent sample t-test obtaining an insignificant value $(p>0.05)$ on the aspect of anatomy coverage and obtaining significant value $(p<0.05)$ in the aspect of density and contrast and anatomical structure. These results mean

Table 4. Results of image quality assessment and independent sample t-test between conventional and digital indirect methods on mixed tooth period patients' radiograph

\begin{tabular}{lccc}
\hline \multicolumn{1}{c}{ Aspect of image quality assessment } & Mean \pm SD conventional & Mean \pm SD indirect digital & Sig. \\
\hline Anatomy coverage & $3.434 \pm 0.053$ & $3.447 \pm 0.038$ & 0.496 \\
Density and contrast & $2.816 \pm 0.017$ & $3.217 \pm 0.025$ & $0.001\left(^{*}\right)$ \\
Anatomical structure & $2.796 \pm 0.020$ & $3.370 \pm 0.034$ & $0.002\left({ }^{*}\right)$ \\
\hline
\end{tabular}

Notes: Sig. $(p)=$ Significance ${ }^{*}=$ significant

that there was no significant difference in the aspect of anatomical coverage, while there were significant differences in the aspects of density and contrast and the anatomical structure between conventional and digital indirect methods on the mixed tooth period patients' radiograph.

\section{DISCUSSION}

Based on the research results listed in Table 2, the interobserver agreement and intraobserver agreement tests showed consistent and reliable results, thus, the research can be continued. 
Interobserver agreement and intraobserver agreement test results were high because previously, the perception equation was conducted between assistant lecturer and researcher to reach agreement desired to minimised the error. This agreement was following the theory of Mudjosemedi et al. ${ }^{14}$, which stated that to obtain consistent and reliable data require interobserver agreement test stage and intraobserver agreement. Because of the interobserver and intraobserver have the consistency result so the data have highly reliability to be analysed. The data were then analysed using an independent sample t-test after all of the data showed the normal distribution (Table 3).

The result of independent test sample t-test showed no significant difference in the aspect of anatomical coverage because the $\mathrm{x}$-ray machine used in the conventional and digital indirect method was the same machine, which was Yoshida Panoura X-ray machine (Yoshida Dental Mfg. Co., Ltd., Japan). Thus each method gets exposure with a relatively equal exposure dose of $70-80$ $\mathrm{kVp}$, 8-10 mA and 13-15 s. Another factor that led to differences in results obtained in this study with other research was the manipulation of indirect digital radiographic images (Table 4).

Result of the statistical test of image quality assessment on density and contrast aspect and anatomical structure showed there were significant differences (Table 4.). The results may be related to indirect digital radiographs using a high diagnostic filter so that the density and contrast can be adjusted to the research needs, and small anatomical structures can be seen more clearly. Da Silva et al. ${ }^{15}$ stated that indirect digital radiography was conventional radiography recorded by a video camera or scanner and converted into digital format in a computer through a software program so the result could be adjusted. This result was also following the theory by Sabarudinet al. ${ }^{13}$ and Parissis et al. ${ }^{16}$, which suggested that digital panoramic images on a computer screen can be changed using custom filter, so that the manipulated digital indirect radiograph image is capable of producing better image resolution. It could be suggested that radiographic image quality between conventional and digital methods are different significantly.

The poor quality of the radiograph image will affect the diagnosis and treatment plan, requiring good image quality to support the correct and accurate dentist diagnosis. Another factor that may affect the quality of the panoramic radiograph image is the quality of $\mathrm{x}$-ray equipment. ${ }^{5,17}$ Radiographic capabilities may be a factor that may affect the quality of the panoramic radiograph image. ${ }^{18}$

Panoramic radiographs of mixed tooth periods can be used to assist dentists in diagnosing childhood disorders. Bekiroglu et al. ${ }^{19}$ stated that panoramic radiographs on mixed tooth period patients' radiograph may help dentists to diagnose early childhood dental pathology and anomalies, resulting in a better prognosis. ${ }^{15}$ Panoramic radiography has a relatively low dose that is suitable for use in pediatric period patients mixed teeth. ${ }^{16}$ Panoramic radiographic image quality of conventional methods is comparable to panoramic radiographic images of digital methods when used to evaluate the condition of third molar teeth. ${ }^{16}$ Conventional radiographs of conventional methods are superior to digital methods in all aspects of comparison (enamel, dentin and root canal filling) except for the clarity of apical pathology conditions. $^{20}$

\section{CONCLUSION}

There are differences in the aspects of density and contrast, and anatomical structure of the results of the panoramic radiograph image quality assessment between conventional and digital indirect methods on mixed tooth period patients' radiograph.

\section{REFERENCES}

1. White SC, Pharoah MJ. Oral Radiology: Principles and Interpretation. $8^{\text {th }}$ ed. St. Louis: Mosby-Elsevier; 2018. p. 347.

2. Yasar F, Yesilova E, Apaydin B. The effects of compression on the image quality of digital panoramic radiographs. Clin Oral Investig. 2012; 16(3): 719-26. DOI: 10.1007/s00784011-0587-y

3. Rushton VE, Horner K, Worthington HV. The quality of panoramic radiographs in a sample of general dental practices. Br Dent J. 1999; 186(12): 630-3. DOI: 10.1038/sj.bdj.4800182

4. Whaites E, Drage N. Essentials of Dental 
Radiography and Radiology. $5^{\text {th }}$ ed. London: Churchill Livingstone; 2013. pp. 5-6, 174, 1824.

5. Bansal GJ. Digital radiography. A comparison with modern conventional imaging, Postgrad Med J. 2006; 82(969): 425-8. DOI: $10.1136 /$ pgmj.2005.038448

6. Sanderink GC, Huiskens $R$, van der Stelt PF, Welander US, Stheeman SE. Image quality of direct digital intra-oral $x$-ray sensor in assessing root canal length. The RadioVisioGraphy, Visualix/VIXA, Sens-A-Ray, and Flash Dent systems compared with Ektaspeed films. Oral Surg Oral Med Oral Path. 1994; 78(1): 125-32. DOI: $10.1016 / 0030-4220$ (94)90128-7

7. Farman AG. Panoramic Radiology: Seminars on Maxillofacial Imaging and Interpretation. Berlin: Springer Science \& Business Media; 2007. pp. 15, 25-30.

8. Iannucci JM, Howerton LJ. Dental Radiography: Principles and Techniques. $4^{\text {th }}$ ed. Philadelphia: Saunders-Elsevier; p. 268.

9. Mathewson RJ. Primosch RE. Fundamental of Pediatric Dentistry. $3^{\text {rd }}$ ed. New Delhi: Quintessence India; 2014. p. 31.

10. White SC, Pharoah MJ. Oral Radiology: Principles and Interpretation. $5^{\text {th }}$ ed. St. Louis: Mosby-Elsevier; 2004. pp. 175-9.

11. Madan K, Baliga S, Thosar N, Rathi N. Recent advances in dental radiography for pediatric patients: A review. J Med Radiol Pathol Surg. 2015; 1(2): 21-25. DOI: 10.15713/ins.jmrps. 11

12. Notoatmodjo S. Metodologi penelitian kesehatan. Jakarta: Rineka Cipta; 2012. pp. 127-8.

13. Sabarudin A, Tiau YJ. Image quality assessment in panoramic dental radiography: A comparative study between conventional and digital systems. Quant Imaging Med Surg. 2013; 3(1): 43-8. DOI: 10.3978/j.issn.2223-

\section{$\underline{4292.2013 .02 .07}$}

14. Mudjosemedi M, Widyaningrum R, Gracea RS. Perbedaan hasil pengukuran horizontal pada tulang mandibula dengan radiograf panoramik. 2015; 1(1): 78-85. DOI: $10.22146 /$ majkedgiind. 9010

15. da Silva JMG, de Melo Castilho JC, Matsui RH, Matsui MY, Gomes MF. Comparative study between conventional and digital radiography in cepphalometric analysis. J Health Sci Inst. 2011; 29(1): 19-22.

16. Parissis N, Angelopoulos C, Mantegari S, Karamanis S, Masood F, Tsirlis A. A comparison of panoramic image quality between a digital radiography stroge phospor system and a filmbased system. J Contemp Dent Pract. 2010; 11(1): E009-16. DOI: 10.5005/jcdp-11-1-9

17. Suryani IR, Villegas NS, Shujaat S, De Grauwe A, Azhari A, Sitam S, et al. Image quality assessment of pre-processed and postprocessed digital panoramic radiographs in paediatric patients with mixed dentition. Imaging Sci Dent. 2018; 48(4): 261-8. DOI: 10.5624/isd.2018.48.4.261

18. Dhillon M, Raju SM, Verma S, Tomar D, Mohan RS, Lakhanpal $M$, et al. Positioning errors and quality assessment in panoramic radiography. Imaging Sci Dent. 2012; 42(4): 207-12. DOI: 10.5624/isd.2012.42.4.207

19. Bekiroglu N, Mete S, Ozbay G, Yalcinkaya S, Kargul B. Evaluation of panoramic radiographs taken from 1,056 Turkish children. Niger J Clin Pract. 2015; 18(1): 8-12. DOI: 10.4103/1119$\underline{3077.146965}$

20. Ajmal M, Elshinawy MI. Subjective image quality comparison between two digital dental radiographic systems and conventional dental film. Saudi Dent J. 2014; 26(4): 145-50. DOI: 10.1016/j.sdentj.2014.05.007 